\title{
In fond remembrance and tribute to Dr. Kuan-Teh Jeang, M.D., Ph.D
}

\author{
Jay Rappaport
}

Received: 11 February 2013 / Accepted: 20 February 2013 / Published online: 16 March 2013

(C) Journal of NeuroVirology, Inc. 2013

In the neurovirology community, we are deeply saddened by the sudden passing of Dr. Kuan-Teh Jeang. Teh was a dear colleague and friend who I came to know, initially as postdoctoral fellows in the laboratory of the esteemed Dr. George Khoury in the Laboratory of Molecular Virology at NIH. This was a dynamic time in the Khoury Lab, as Gilbert Jay was a section head and several other senior postdocs and investigators in the lab included John Brady (who we also lost too soon), Ravi Dhar, Jeff Green, Chou-Zen (Joe) Giam, Kamel Khalili, Lou Laimins (who had recently finished), and Michael Nerenberg, among others. Having trained in Dr. Khoury's laboratory where the concept of transcriptional enhancers was established using SV40 as a model, Teh had embarked on studies demonstrating the activation of HTLVI transcription by the viral Tax protein. He further demonstrated that transcriptional activation occurred through interaction with cellular factors recognizing the 21 base pair repeats within the HTLV-I long terminal repeat/promoter. After Dr. Khoury's untimely death (also at a young age), Teh moved to the Laboratory of Molecular Microbiology at NIH and became Chief of the Molecular Virology Section. Here, Teh made highly important contributions to our understanding of HTLV-I (the causative agent of adult T cell leukemia) and HIV. In his further studies with HTLV-1, Teh identified an important mechanism involved in carcinogenesis. In these studies, Teh demonstrated the interaction of Tax with the centrosome machinery during mitosis, providing a means for generating chromosomal abnormalities leading to cancer. He also demonstrated the role of Tax in abrogating the function of the mitotic checkpoint protein, MAD1, as a means for escape of cells with chromosomal abnormalities, leading to tumor formation. In his studies

J. Rappaport $(\bowtie)$

Department of Neuroscience, Center for Neurovirology,

Temple University School of Medicine, Philadelphia, PA, USA

e-mail: jayrapp@temple.edu related to HIV, he was one of the first investigators to describe the interaction of Tat with the "nascent" HIV-1 Tat activation response element (TAR) RNA as part of the mechanism leading to transactivation of HIV transcription. Tat proved also to interact with TAR in the context of coactivating cellular factors. Teh further described the interaction of Tat with other proteins including RNAse III or Dicer, an enzyme that processes micro RNAs (miRNA) and short interfering RNAs. Based on Teh's studies, one of the important roles of Tat in the viral life cycle, in addition to transcription activation, appears to be the suppression of RNAmediated (i.e., miRNA) silencing mechanisms. Teh's studies were highly sophisticated and innovative. He had undertaken a major effort to identify cellular genes contributing to HIV replication by implementing a short hairpin RNA inhibition screening approach using $\mathrm{T}$ cell clones transduced with shRNAs. These studies revealed 252 genes that contribute to productive HIV infection in T cells. These genes could be attractive targets for HIV therapy. His work was also supported by the Bill and Melinda Gates foundation's "Grand Challenges in Global Health" during the past few years, where Teh was testing the feasibility of a viral interference approach as a way to prevent or cure HIV infection.

Teh was a highly energetic and dynamic individual who was a respected leader in both his pursuit of scientific discovery as well as his service to the scientific community. He established the highly successful and prestigious open access journal, Retrovirology, and received the Biomed Central's "Editor of the Year" award in 2010. He also was honored at the 15th International Conference on Human Retrovirology in 2011, receiving the Dale McFarlin Award of the International Retrovirology Association. Teh was also an editor of Cell and Bioscience, associate editor for Cancer Research, and served on the editorial boards of prestigious journals such as the Journal of Virology and Journal of Biological Chemistry. He played a major role in the establishment of the George Khoury Memorial Lecture, which honors 
Dr. Khoury, as a superb scientist and mentor for postdoctoral fellows, at NIH. This lectureship has been awarded annually to a number of the most notable scientists of our time. Teh had been awarded this lectureship just last year. The full video of this lecture is available at http://blogs.biomedcentral.com/ rvblog/2012/10/29/kuan-teh-jeang-gives-2012-georgekhoury-lecture/. This lecture highlights some of Teh's many scientific contributions of which included more than 300 published papers as well as six books where he was editor.

Teh had a large presence at NIH, in the retrovirology community, and in the scientific community at large. He will be deeply missed professionally and personally by his many friends and colleagues. Our thoughts and sympathies go out to his family, including his wife Diane, and three children, David, John, and Diana.

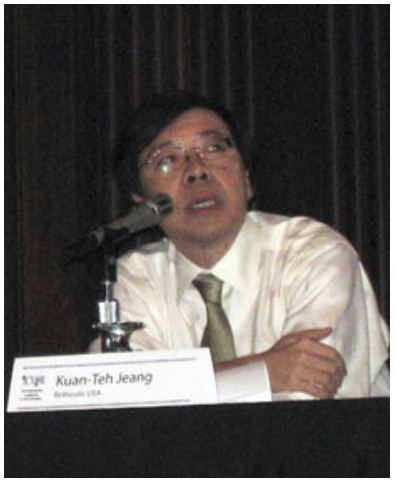

Dr. Kuan-Teh Jeang chairing a session at the International Conference on Viral Oncology held in Philadelphia in the Fall of 2008. 